\title{
A new set of 182 microsatellites for Eucalyptus: characterization and mapping in a four-species consensus linkage map
}

\author{
Danielle Faria ${ }^{1 *}$, Eva Mamani ${ }^{1}$, Juliana Sena ${ }^{1}$, Alexandre Alves ${ }^{1}$, Clarissa Falcao ${ }^{1}$, Rodrigo Lourenço ${ }^{1}$, \\ Georgios Pappas ${ }^{2}$, Dario Grattapaglia² \\ From IUFRO Tree Biotechnology Conference 2011: From Genomes to Integration and Delivery \\ Arraial d'Ajuda, Bahia, Brazil. 26 June - 2 July 2011
}

\section{Background}

Eucalyptus is the most widely planted hardwood crop in the tropical and subtropical world. Plantations of Eucalyptus species supply high-quality wood for industrial applications and are important sources of carbon neutral renewable energy in Brazil. E. grandis and E. urophylla and their hybrids are the most widely planted species in fast growing commercial forests in Brazil. E. globulus is the preferred raw material by the mills generating a pulp that is considered superior by the market. However as a pure species it does not grow adequately in Brazil but performs well in hybrid combinations. Breeding programs have increasingly incorporated E. globulus germplasm in fast moving elite populations. Molecular breeding in such populations will require information on markers, comparative mapping and QTL validation across pedigrees involving these different species. Highly multiallelic and transferable microsatellites not only are excellent tools for individual identification, but also provide robust and efficient framework genetic maps that serve well for mapping thousands of bialellic higher throughput markers such as Single Nucleotide Polymorphisms (SNPs) and Diversity Array Technology (DArT). Furthermore microsatellites provide a powerful way for QTL validation across species. We describe the development and characterization of 182 new microsatellites, most of them derived from ESTs and some from a genomic shotgun library. These markers, together with other previously developed ones were used to build a

\footnotetext{
* Correspondence: danyafp@gmail.com

'Plant Genetics Laboratory, EMBRAPA Genetic Resources and Biotechnology, PqEB, CEP 70770-970, DF, Brazilia, Brazil

Full list of author information is available at the end of the article
}

consensus map involving three different pedigrees derived from intercrossing four species of Eucalyptus.

\section{Methods}

The source of ESTs used to mine microsatellites and the methods used to select loci and design primers were described earlier [1,2]. Data from a sample sequencing experiment, carried out back in 2003 using a Sanger sequenced shotgun genomic library, was used for microsatellite discovery (R.T. Lourenço, unpublished). Microsatellite, primer pairs were initially screened for assay success, polymorphism and inter-specific transferability by colorimetric detection on polyacrylamide gels. Selected loci had their forward primer re-synthesized with a fluorescence label and used in downstream genotyping. Loci were characterized using a set of 32 unrelated individuals each of E. grandis and E. globulus. Map construction was carried out for three different pedigrees of Eucalyptus one of them being the pedigree used earlier for a reference map construction [3]. Mapping was conducted using JoinMap 3.0 [4] with a minimum LOD score of 10. and marker order determined with the default mapping module parameters. Parameters of genetic information content (PIC polymorphism information content; $\mathrm{PE}=$ probability of paternity exclusion and $\mathrm{PI}=$ probability of identity) were estimated for all newly developed microsatellite markers for each species separately.

\section{Results}

Data mining of 22,298 unigenes provided 1,261 microsatellite loci. Most of them were $(54.71 \%)$ trinucleotide repeats. After all screening steps, 494 microsatellites amplified discrete and polymorphic fragments and 210

(c) 2011 Faria et al; licensee BioMed Central Ltd. This is an open access article distributed under the terms of the Creative Commons Attribution License (http://creativecommons.org/licenses/by/2.0), which permits unrestricted use, distribution, and reproduction in any medium, provided the original work is properly cited. 
were selected for fluorescence based genotyping. From the single-pass genomic shotgun library 41 microsatellites were also selected following then same screening steps. Genetic maps were initially built for each pedigree separately. A consensus map was then built by combining separately the homologous linkage groups of the three maps. The total number of microsatellite markers eventually mapped was 448 including the 234 previously mapped [3] and part of those published but not yet mapped earlier $[1,2]$. The map had an estimated total recombination distance of $1,297 \mathrm{cM}$ and an average distance between adjacent markers of $3.48 \mathrm{cM}$. The linear order of markers was conserved on most linkage groups across the individual pedigree maps and the consensus map.with no evidence of rearrangement of chromosomal blocks. For the 182 newly developed microsatellites characterized the allele size range did not vary between E. grandis and E. globulus. Only 15 loci for E. grandis and 17 loci for E. globulus were monomorphic in the set of individuals genotyped. The average number of alleles was very close in the two species, 4.6 for $E$. grandis and 4.8 for E. globulus. A significant estimate of null allele frequency was found for only seven loci and these coincided for the two species Average PIC, PE and PI for the set of loci were not substantially different between the two species. Furthermore the overall performance of the EST derived and genomic shotgun derived sets of microsatellite did not show any appreciable difference, somehow unexpectedly due to the generally lower polymorphism of genic microsatellites. The ascertainment bias introduced by the much larger set of EST derived microsatellites and rigorous screening applied might have contributed to this.

\section{Conclusion}

This work summarizes the development and characterization of a new set of 182 new microsatellites markers and presents a relatively dense microsatellite marker consensus map involving four different species of Eucalyptus. The new 182 microsatellites developed are robust and polymorphic enough to be used for applications in breeding programs that involve individual identification as well as for comparative QTL mapping and marker assisted selection.

\footnotetext{
Acknowledgments

This work was supported by the Brazilian Ministry of Science and Technology through CNPq grant 577047/2008-6 and FAP-DF Grant NEXTREE 193.000.570/2009 and EMBRAPA Macroprogram 2 project grant 02.07.01.004

\section{Author details}

'Plant Genetics Laboratory, EMBRAPA Genetic Resources and Biotechnology, PqEB, CEP 70770-970, DF, Brazilia, Brazil. ²Plant Genetics Laboratory, EMBRAPA Genetic Resources and Biotechnology, CEP 70770-970, DF, Brazilia, Brazil, and Graduate Program in Genomic Sciences Biotechnology and
}

Universidade Católica de Brasília, SGAN Qd 916, CEP 70790-160, DF, Brasília, Brazil.

Published: 13 September 2011

References

1. Faria DA, Mamani EMC, Pappas GJ, Grattapaglia D: Genotyping systems for Eucalyptus based on tetra-, penta-, and hexanucleotide repeat EST microsatellites and their use for individual fingerprinting and assignment tests. Tree Genetics \& Genomes 2011, 7(1):63-77.

2. Faria DA, Mamani EMC, Pappas MR, Pappas GJ, Grattapaglia D: A Selected Set of EST-Derived Microsatellites, Polymorphic and Transferable across 6 Species of Eucalyptus. Journal of Heredity 2010, 101(4):512-520.

3. Brondani RPV, Williams ER, Brondani C, Grattapaglia D: A microsatellitebased consensus linkage map for species of Eucalyptus and a novel set of 230 microsatellite markers for the genus. Bmc Plant Biology 2006, 6:1-16.

4. Van Ooijen JWV, R E: JoinMap 3.0, Software for calculation of genetic linkage maps. Wageningen, The Netherlands: Plant Research International; 2001.

doi:10.1186/1753-6561-5-S7-P34

Cite this article as: Faria et al:: A new set of 182 microsatellites for Eucalyptus: characterization and mapping in a four-species consensus linkage map. BMC Proceedings 2011 5(Suppl 7):P34.

\section{Submit your next manuscript to BioMed Central} and take full advantage of:

- Convenient online submission

- Thorough peer review

- No space constraints or color figure charges

- Immediate publication on acceptance

- Inclusion in PubMed, CAS, Scopus and Google Scholar

- Research which is freely available for redistribution 